\title{
Article
}

\section{Adsorption Behavior of Various Metal Ions in Nitrite Medium and Separation of Some Metals by Anion Exchange}

\author{
Yuezhou WEI, Tsuyoshi ARAI and Mikio KUMAGAI \\ Kashiwa Laboratory, Institute of Research and Innovation, 1201 Takada, Kashiwa 277-0861, Japan \\ Qiming FENG \\ Department of Mineral Engineering, Central South University, Changsha 410083, P.R. China
}

(Manuscript submitted February 6, 2003; accepted March 31, 2003)

\begin{abstract}
The purpose of this work is to investigate the adsorption behavior of various metals ions and the possibility of their separation in nitrite medium by anion exchange. Distribution coefficients of about 40 metals from nitrite solution onto a conventional anion exchanger (IRA-900) and a new type anion exchanger (AR-01) containing benzimidazoles as functional group were systematically measured. Based on the different adsorbability, some metal pairs such as $\mathrm{Zn}$ (II)/Cd(II) and $\mathrm{Ga}(\mathrm{III}) / \mathrm{In}$ (III) in $\mathrm{NaNO}_{2}-\mathrm{HNO}_{3}$ solution, were successfully separated from each other by column chromatography.
\end{abstract}

\section{Introduction}

As an efficient separation method of metal ions in solution, ion exchange technology has found wide applications in analytical chemistry, water treatment, metallurgical and radiochemical separation during the past decades. Anion exchange behavior of most metal ions in many kinds of aqueous media including chloride, nitrate, sulfate, fluoride, carbonate and the combination of these media have been extensively studied.[1,2] However, until now very little attention has been given to the anion exchange of metal ions in nitrite medium. It was reported that some metal ions can form anionic nitro-complexes in nitrite medium.[3] In our previous work, we investigated the adsorption and separation behavior of the three typical transition metals of $\mathrm{Co}$ (II), $\mathrm{Ni}$ (II) and $\mathrm{Cu}$ (II) in nitrite solution with a commercial anion exchanger, Amberlite IRA-900 and a novel silica-based anion exchanger, AR-01.[4] It was found that successful separations of $\mathrm{Co}$ (II) from $\mathrm{Ni}$ (II), and $\mathrm{Cu}$ (II) from $\mathrm{Ni}$ (II) were achieved by column chromatography based on their different adsorbability.

In this study, to evaluate the adsorption behavior of various metal ions from nitrite medium onto anion exchanger, distribution coefficients of about 40 metal ions in the aqueous solutions containing 0-3 $M$ $\left(M=\mathrm{mol} / \mathrm{dm}^{3}\right) \mathrm{NaNO}_{2}$ and $0.1 M \mathrm{HNO}_{3}$ were measured systematically with the anion exchangers of IRA-900 and AR-01. Furthermore, separation behavior of some typical metal pairs such as $\mathrm{Zn}(\mathrm{II}) / \mathrm{Cd}(\mathrm{II})$ and $\mathrm{Ga}(\mathrm{III}) / \mathrm{In}(\mathrm{III})$ was demonstrated by column chromatography based on their different adsorbability.

\section{Experimental}

\subsection{Materials}

The structure and property of the anion exchangers are shown in Table 1. The bead diameter of IRA-900 is 
450-550 $\mu \mathrm{m}$ and the capacity is $4.2 \mathrm{eq} / \mathrm{kg}-\mathrm{resin}$. AR-01 is a new type of anion exchanger prepared in our laboratory. It consists of the macroreticular resin embedded in porous silica particles with a mean particle size of $50 \mu \mathrm{m}$. The resin contains $\mathrm{N}$-methylbenzimidazole (weak-base) and N,N'-dimethylbenzimidazolium (strong-base) groups as exchange sites. The total exchange capacity and strong-base capacity are $3.4 \mathrm{eq} / \mathrm{kg}$-resin and 2.0 eq/kg-resin, respectively.

\subsection{Batch Adsorption}

The sample solutions containing a metal were prepared by dissolving its nitrate salt in $\mathrm{HNO}_{3}-\mathrm{NaNO}_{2}$ solution. About $1 \mathrm{~g}$ of anion exchanger and $20 \mathrm{~cm}^{3}$ of a sample solution containing $10 \mathrm{mM}$ of metal ion, $0.1 \mathrm{MHNO}_{3}$ and 0-3 $M \mathrm{NaNO}_{2}$, were mixed in a glass flask. The flask was placed in the shaking water bath maintained at $298 \mathrm{~K}$ and was shaken for 2 hours. Then the solution was separated from the anion exchanger by filtration and the metal concentrations in the solution were analyzed by ICP-AES. The anion exchanger was washed and then dried at $333 \mathrm{~K}$ in vacuum for 12 hours. The Table 1 Structure and property of the anion exchangers

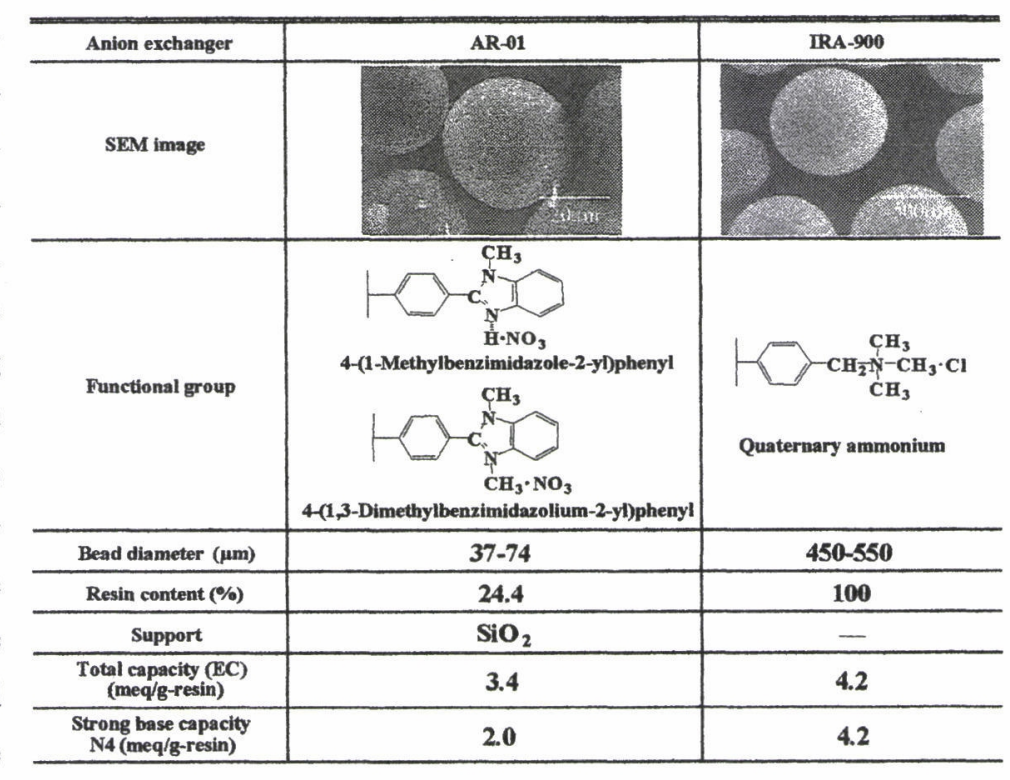
distribution coefficient $\left(K_{d}\right)$ was calculated by $E q .(1)$.

$$
K_{d}=\frac{C_{0}-C_{S}}{C_{S}} \times \frac{V_{S}}{W_{R}} \quad\left(\mathrm{dm}^{3} / \mathrm{kg}-\mathrm{resin}\right)
$$

where $C_{o}$ and $C_{s}$ denote the metal concentration in the aqueous phase before and after adsorption, respectively. $W_{R}$ indicates the weight of the dry resin $(\mathrm{kg})$ and $V_{S}$ indicates the volume of the aqueous phase $\left(\mathrm{dm}^{3}\right)$.

\subsection{Column Separation}

Separation experiments were conducted using a Pyrex-glass column with $10 \mathrm{~mm}$ internal diameter and 500 $\mathrm{mm}$ length. The column and the throughput solutions were kept at $298 \mathrm{~K} .30 \mathrm{~cm}^{3}$ of a sample solution containing 6-10 $\mathrm{mM}$ of metal ions, $0.5 \mathrm{MNaNO}_{2}$ and $0.1 \mathrm{MHNO}_{3}$ was fed to the column at flow rate of $0.3 \mathrm{dm}^{3} / \mathrm{h}$. Then washing and eluent solutions were supplied to the column at the same flow rate, successively. The effluent from the column was collected by auto-fractional collector in $10 \mathrm{~cm}^{3}$ aliquots and analyzed by ICP-AES.

\section{Results and Discussion}

\subsection{Adsorption Behavior}

The effects of $\mathrm{NaNO}_{2}$ concentration on distribution coefficients of various metals onto IRA-900 are shown in Fig. 1 to Fig. 3. Note that the metal ions except Mo(VI) and Cd(II) showed almost no or very weak adsorption on the anion exchanger without $\mathrm{NaNO}_{2}$. However, the adsorption of $\mathrm{In}(\mathrm{III}), \mathrm{Co}(\mathrm{II}), \mathrm{V}(\mathrm{V}), \mathrm{Cd}(\mathrm{II}), \mathrm{Mo}(\mathrm{VI}), \mathrm{Ga}$ (III), $\mathrm{Zn}$ (II), $\mathrm{Cu}(\mathrm{II}), \mathrm{Cu}(\mathrm{I}), \mathrm{Ag}(\mathrm{I}), \mathrm{Pb}(\mathrm{II}), \mathrm{Cr}$ (III) and $\mathrm{Al}$ (III) increased significantly with increasing nitrite concentration and the $K_{d}$ of some ions showed a maximum value at around $1 M \mathrm{NaNO}_{2}$ (Fig. 1 and Fig. 2). On the other hand, the metals such as $\mathrm{Li}(\mathrm{I}), \mathrm{Ca}(\mathrm{II}), \mathrm{Sr}(\mathrm{II})$, and the trivalent rare earths exhibited almost no or only slight adsorption over 0-3 $M \mathrm{NaNO}_{2}$ and the $K_{d}$ values are less than $4 \mathrm{dm}^{3} / \mathrm{kg}$ (Fig.3). From the results of $K_{d}$ measurement, the adsorbability of the metal ions from nitrite solution onto anion exchanger can be summarized as follows:

(1) Strong adsorption ions ( $\left.K_{d}>100\right)$ : In(III), Co(II), V(V), Cd(II), Mo(VI), U(VI), Ru(III). 
(2) Moderate adsorption ions ( $\left.K_{d}=20-100\right): \mathrm{Zn}(\mathrm{II}), \mathrm{Cu}$ (II), $\mathrm{Cu}$ (I), $\mathrm{Ag}(\mathrm{I}), \mathrm{Pb}(\mathrm{II}), \mathrm{Cr}$ (III), $\mathrm{Ga}(\mathrm{III}), \mathrm{Al}(\mathrm{III})$.

(3) No or very weak adsorption ions $\left(K_{d}<5\right): \mathrm{Ni}(\mathrm{II}), \mathrm{Mn}(\mathrm{II})$, alkali metals, alkaline earths and rare earths.

(4) Some metal ions such as $\mathrm{Fe}$ (II), $\mathrm{Fe}$ (III), $\mathrm{Sn}$ (IV), $\mathrm{Hg}$ (I), $\mathrm{Hg}$ (II) and $\mathrm{Zr}$ (IV) were found to precipitate in the nitrite solution probably due to hydrolysis reactions.

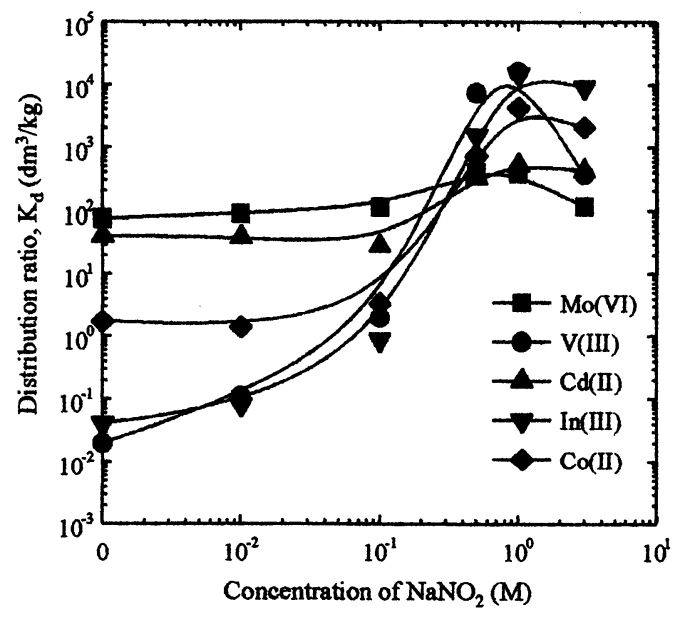

Fig.1 Effect of nitrite concentration on the adsorption of Mo(VI), V(III), Cd(II), In(III) and Co(II) on IRA-900

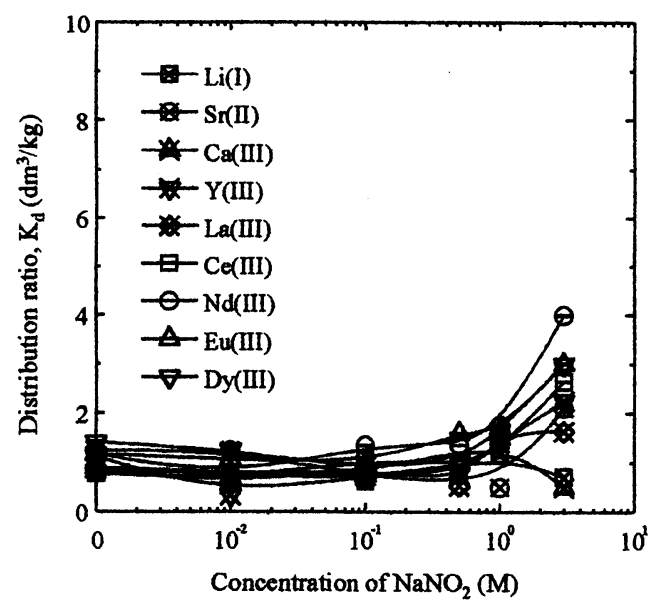

Fig. 3 Effect of nitrite concentration on the adsorption of $\mathrm{Li}(\mathrm{I}), \mathrm{Sr}(\mathrm{II}), \mathrm{Ca}$ (II) and trivalent rare earths on IRA-900

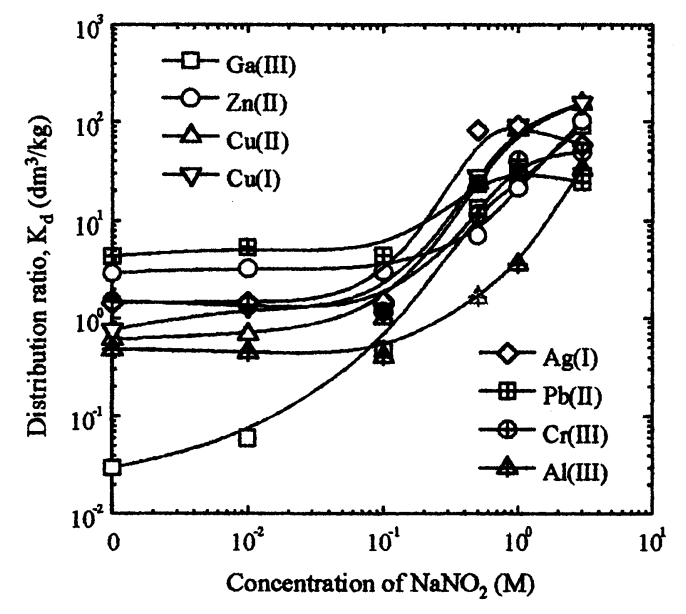

Fig.2 Effect of nitrite concentration on the adsorption of $\mathrm{Ga}$ (III), $\mathrm{Zn}$ (II), $\mathrm{Cu}$ (II), $\mathrm{Cu}$ (I), $\mathrm{Ag}$ (I), $\mathrm{Pb}$ (II), $\mathrm{Cr}$ (III) and $\mathrm{Al}(\mathrm{III})$ on IRA-900

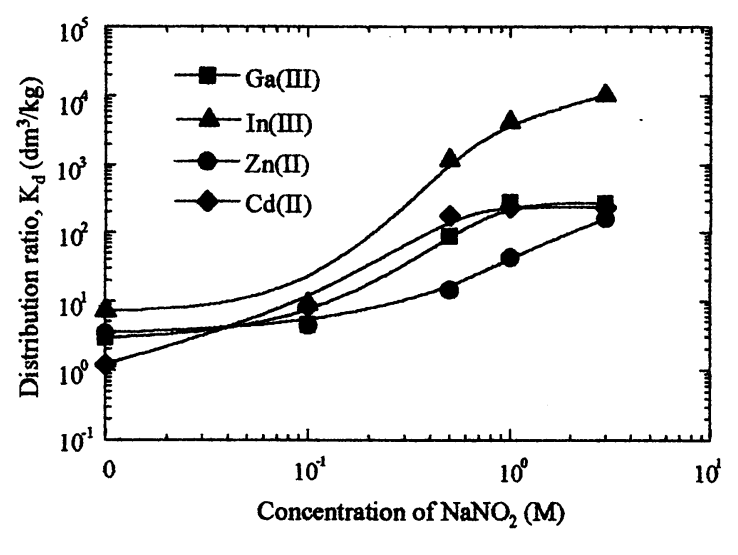

Fig.4 Effect of nitrite concentration on the adsorption of $\mathrm{Ga}$ (III), In(III), $\mathrm{Zn}$ (II) and Cd(II) on AR-01

Fig.4 illustrates the $K_{d}$ values of $\mathrm{Ga}$ (III), $\mathrm{In}(\mathrm{III}), \mathrm{Zn}$ (II) and $\mathrm{Cd}$ (II) from nitrite solution onto AR-01 as a function of $\mathrm{NaNO}_{2}$ concentration. As seen, the adsorption of these metal ions was significantly promoted by increasing $\mathrm{NaNO}_{2}$ concentration and the adsorption behavior is similar to the results shown in Fig. 1 and Fig. 2. On the other hand, the $K_{d}$ value of In(III) is much higher than that of the same group element, $\mathrm{Ga}(\mathrm{III})$, and the separation factor $(S F)$ between $\mathrm{In}(\mathrm{III})$ and $\mathrm{Ga}$ (III) is $10-20$ at $0.5-1 \mathrm{MNaNO}_{2}$. Similarly, the adsorption of $\mathrm{Cd}$ (II) is stronger than $\mathrm{Zn}$ (II) and the $S F$ for $\mathrm{Cd}(\mathrm{II}) / \mathrm{Zn}$ (II) is about 10.

In nitrite solution, some metal ions can form anionic nitro-complexes and show adsorbability on an anion exchanger. The complex formation and adsorption reactions of metal ions in nitrite medium can be expressed as

$$
\begin{aligned}
& \mathrm{M}^{\mathrm{m}+}+\mathrm{nNO}_{2}^{-}=\mathrm{M}\left(\mathrm{NO}_{2}\right)_{\mathrm{n}}{ }^{\mathrm{m}-\mathrm{n}} \\
& \mathrm{M}\left(\mathrm{NO}_{2}\right)_{\mathrm{n}}^{\mathrm{m}-\mathrm{n}}+(\mathrm{n}-\mathrm{m})\left(\mathrm{R}^{+} \cdot \mathrm{NO}_{2}{ }^{-}\right)=\mathrm{R}_{(\mathrm{n}-\mathrm{m})} \cdot \mathrm{M}\left(\mathrm{NO}_{2}\right)_{\mathrm{n}}{ }^{\mathrm{m}-\mathrm{n}}+(\mathrm{n}-\mathrm{m}) \mathrm{NO}_{2}^{-}
\end{aligned}
$$


Where $\mathrm{m}, \mathrm{n}$ and $\mathrm{R}$ denote the charge number of metal ion, the coordination number of nitro-complexes and the fixed-ionic-group of anion exchanger, respectively. The adsorbability of metal ions is considered to depend on their complexation ability with $\mathrm{NO}_{2}^{-}$. In many cases of anion exchange for metal complexes, a maximum adsorption is observed in a certain ligand concentration based on the equilibria of complex formation and the competitive adsorption of anionic ligand.[5,6] As shown in Fig. 1, Fig. 2 and Fig. 4, the maximum $K_{d}$ values of some metals were observed at around $1 M$ nitrite.

\subsection{Separation behavior of some metal pairs}

From the above $K_{d}$ measurement results, it was found that some metal pairs of the same group such as $\mathrm{Ga}(\mathrm{III}) / \mathrm{In}$ (III), $\mathrm{Zn}$ (II)/Cd(II) and $\mathrm{Co}$ (II)/Ni(II) show significantly different adsorbability from nitrite solution onto an anion exchanger. This indicates that efficient separation between these metal pairs can be expected by column chromatography. In our previous studies, if was found that compared to IRA-900, AR-01 shows faster adsorption-elution kinetics and higher stability in nitric acid medium.[4,7,8] In this work, the separations of $\mathrm{Ga}$ (III) from $\mathrm{In}$ (III) and $\mathrm{Zn}$ (II) from $\mathrm{Cd}$ (II) were attempted by using AR-01 packed column.

Fig. 5 shows the results of the separation experiment for a sample solution containing $6 \mathrm{mM} \mathrm{Ga}(\mathrm{III}), 10 \mathrm{mM}$ In(III), $0.5 M \mathrm{NaNO}_{2}$ and $0.1 M \mathrm{HNO}_{3}$ by an AR-01 packed column. As can be seen, $\mathrm{Ga}$ (III) leaked out the column firstly with the sample solution and the first part of $0.1 \mathrm{M} \mathrm{HNO}_{3}$ eluent solution. The In(III) was strongly adsorbed and then eluted off effectively by $0.1 \mathrm{MHNO}_{3}$, showing a sharp elution peak. Successful separation between $\mathrm{Ga}$ (III) and $\mathrm{In}(\mathrm{III})$ was achieved. A separation experiment for a sample solution containing 9-10 $\mathrm{mM}$ $\mathrm{Zn}$ (II) and $\mathrm{Cd}(\mathrm{II}), 0.5 \mathrm{MNaNO}_{2}$ and $0.1 \mathrm{MHNO}_{3}$ was carried out by using the AR-01 packed column, and the results are presented in Fig. 6. As seen, compared to $\mathrm{Cd}(\mathrm{II})$, the adsorption of $\mathrm{Zn}$ (II) was weaker and leaked out the column firstly. $\mathrm{Cd}(\mathrm{II})$ was completely adsorbed and efficiently eluted off by $0.1 M \mathrm{HNO}_{3}$. Perfect separation between $\mathrm{Zn}$ (II) and $\mathrm{Cd}$ (II) was obtained.

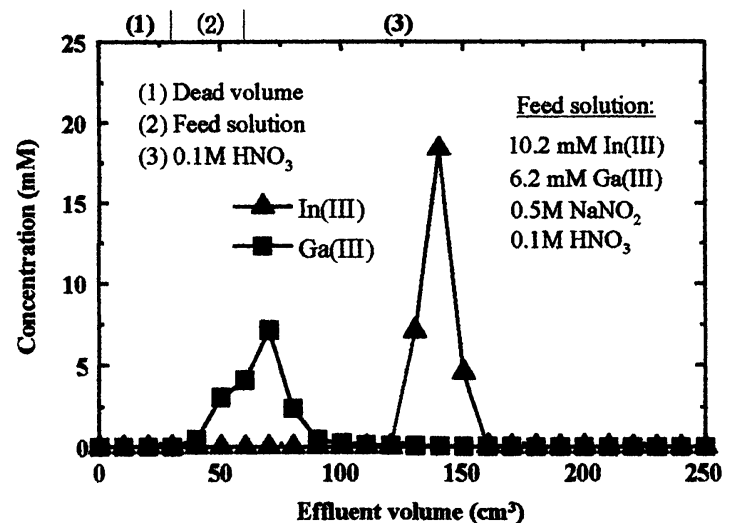

Fig. 5 Results of separation experiment for a $\mathrm{Ga}(\mathrm{III})$ In(III) containing nitrite solution by AR-01 column

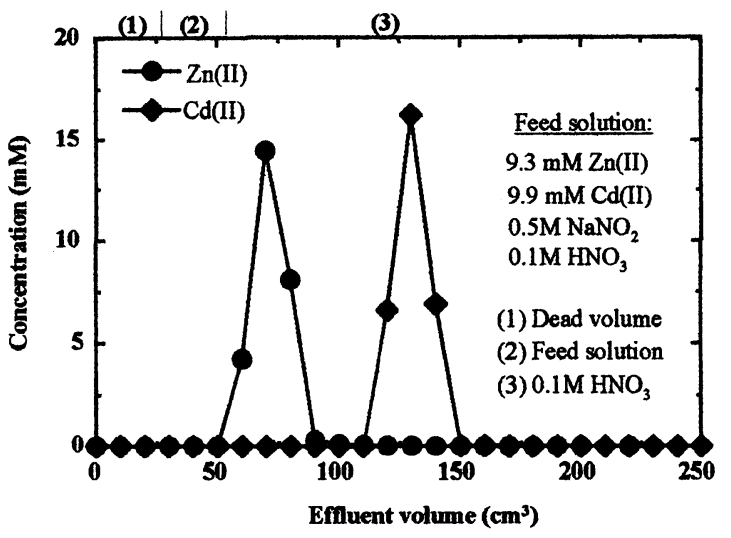

Fig. 6 Results of separation experiment for a $\mathrm{Zn}$ (II)$\mathrm{Cd}(\mathrm{II})$ containing nitrite solution by AR-01 column

\section{References}

1) L.R. Bunny, N.E Ballou and J. Pascual, S. Foti, Anal. Chem., 31, 324-326 (1959).

2) E. Akatsu, Report of JAERI, JAERI-M 7168, 1-45 (1977).

3) E. Hogfeldt Eds., "Stability Constants of Metal-Ion Complexes", Pergamon Press, (1982), Part A, pp.118-119.

4) Y.-Z. Wei, Q.-M. Feng, T. Arai and M. Kumagai, Solvent Extr. Ion Exch., 20, $561-573$ (2002)

5) F. Helfferich, "Ion Exchange", Mcgraw-Hill, New York (1962), pp.205-209.

6) J.D. Navratil, J. Nucl. Sci. Technol., 26, 735-743 (1989).

7) S. Iwasa, T. Arai, Y.-Z. Wei, M. Kumagai, K. Murata and K. Takeda, J. Ion Exchange, 12, 40-46 (2001).

8) J.D. Navratil and Y.-Z. Wei, Nukleonika, 46, 75-80 (2001). 